\title{
Meeting on childhood obesity in the Eastern Mediterranean Region ${ }^{1}$
}

Citation: Meeting on childhood obesity in the Eastern Mediterranean Region. East Mediterr Health J. 2022;28(1):78-79. https://doi. org/10.26719/2021.28.1.78

Copyright (C) World Health Organization (WHO) 2022. Open Access. Some rights reserved. This work is available under the CC BY-NC-SA 3.0 IGO license (https://creativecommons.org/licenses/by-nc-sa/3.o/igo).

Obesity and overweight among children and young people are major public health challenges affecting almost half of adults, over a quarter of adolescents, and nearly $6 \%$ of under-five children in the Eastern Mediterranean Region (EMR) (1). They are associated with increased risks for, as well as severity and duration of, other diseases. This deadly interplay is associated with increases in deaths and disability in the Region as already observed in COVID-19 patients (1).

In 2019, the Region adopted recommendations of the World Health Organization (WHO) Commission on Ending Childhood Obesity (2) through its Strategy on Nutrition for the Eastern Mediterranean Region 20202030 (3), and the Regional Framework for Action on Obesity Prevention 2019-2023 (4).

In May 2021, the WHO Eastern Mediterranean Regional Office (WHO EMRO) held a virtual meeting to share experiences on implementing national strategies to prevent childhood obesity and identify needs and opportunities for support and collaborations. The meeting provided a forum to discuss priority actions to achieve the global goals of no increase in childhood overweight by 2025 (5) and halting the rise in adult obesity by 2025 (6).

\section{Summary of discussions}

Participants in the meeting emphasized the importance of a multisectoral approach to tackling childhood overweight and obesity and the development of dietary guidelines for preventing them.

In 2017, UAE launched a comprehensive obesity prevention framework which has helped in the implementation of a sugar-sweetened beverage tax, introduction of front-of-pack labelling, development of school canteen guidelines, and strengthened implementation of the International Code of Marketing of Breast-milk Substitutes.

Using a multi-component approach, Saudi Arabia implemented interventions to limit consumption of sugars, salts and fats, including reformulation of packaged and fast foods and establishment of nutritional criteria for infant and young children's foods. The country now requires food service establishments to declare the calories and allergens on their food menus.

In Iran, a healthy school canteen policy was introduced that prohibits foods high in fats, sugars and/or salts in schools alongside nutrition education, counselling and growth monitoring; and reformulation of foods to reduce salt, sugar and fat levels.

Multisectoral coordination by Morocco helped strengthen screening and taxing of sugar-sweetened beverages and facilitated the development of guidelines on food preparation for schools, legislation on front-ofpack labelling, a roadmap for sugar reduction, technical manual for elimination of trans fatty acids in foods, and a draft legislative text to limit trans fatty acids in oils and fats. Kuwait has been monitoring obesity among all age groups for more than 20 years, and estimates overweight among under-5 children at $10.9 \%$ and obesity at 3.7\% (7). Mapping daily trajectories of children in Tunisia has enabled identification of the food environments to which children are exposed.

Promoting breastfeeding was identified as a key element in the prevention of childhood obesity. Oman has been promoting breastfeeding through campaigns, acceleration of accreditation of baby-friendly hospitals, expansion of breastfeeding support in primary healthcare facilities, distribution of free equipment for expressing breastmilk for mothers with COVID-19, and release of a new version of Oman's Code-implementing law, including training on Code monitoring and enforcement.

Another key element participants referred to as contributing to overweight and obesity among children and adolescents is their exposure to advertising and other forms of marketing for foods high in fats, sugars and/or salt. To address this challenge, they recommended regulatory frameworks to monitor and protect children from harmful food marketing and to require the food industry to provide data on their advertising. In this regard, the WHO Regional Office for Europe said they already developed some templates which could be adapted for use in the Eastern Mediterranean Region.

\section{Recommendations}

The meeting recommended that Member States:

- develop monitoring and evaluation frameworks and measures to regulate food marketing to children;

- develop and implement nutrition standards for all foods sold or provided in schools;

- develop and integrate nutrition education modules into school curricula; and 
- integrate nutrition actions into primary health care.

Participants requested WHO/EMRO to provide technical support to Member States to implement these recommendations as well as support region-wide mapping of digital marketing of foods and establishment of a regional network or subgroup on food marketing, drawing lessons from other WHO regions like the European Region.

\section{References}

1. Al-Jawaldeh A, Hammerich A, Doggui R, Engesveen K, Lang K, McColl K. Implementation of WHO Recommended Policies and Interventions on Healthy Diet in the Countries of the Eastern Mediterranean Region: From Policy to Action. Nutrients. 2020; 12(12):3700. https://doi.org/10.3390/nu12123700.

2. World Health Organization. Report of the Commission on Ending Childhood Obesity. Geneva: World Health Organization, 2016. https://apps.who.int/iris/bitstream/handle/10665/204176/9789241510066_eng.pdf?sequence=1.

3. World Health Organization. Strategy on nutrition for the Eastern Mediterranean Region 2020-2030. Cairo: WHO Regional Office for the Eastern Mediterranean, 2019. https://apps.who.int/iris/handle/10665/330059.

4. World Health Organization. Regional framework for action on obesity prevention 2019-2023. Cairo: WHO Regional Office for the Eastern Mediterranean. https://apps.who.int/iris/handle/10665/325833.

5. World Health Organization. Global Targets 2025: To improve maternal, infant and young child nutrition. 2014: https://www. who.int/teams/nutrition-and-food-safety/global-targets-2025.

6. World Health Organization. Global NCD Target Halt the Rise in Obesity. 2016: https://www.who.int/beat-ncds/take-action/polia cy-brief-halt-obesity.pdf.

7. Alqaoud N, Al-Jawaldeh A, Al-Anazi F, Subhakaran M, Doggui R. Trend and Causes of Overweight and Obesity among Pre-School Children in Kuwait. Children (Basel). 2021;8(6):524. doi:10.3390/children8060524. 